\title{
Prevalence and correlates of psychological distress among diabetes mellitus adults in Jilin province in China: a cross- sectional study
}

\author{
Shuang Qiu ${ }^{1}$, Xuan Hong Sun ${ }^{1}$, Wen Ya Liu ${ }^{1}$ ， Joseph Sam Kanu ${ }^{1}$, Ri Li ${ }^{1}$, Qin Ya Yu ${ }^{1}$, Feng Xu Huang ${ }^{2}$, \\ Bo Li ${ }^{\text {Corresp., }}{ }^{1}$, Yang Xiang Zhang ${ }^{3}$ \\ 1 Department of Epidemiology and Biostatistics, School of Public Health, Jilin University, Changchun, China \\ 3 Psychiatry Research Center, Beijing Hui-Long-Guan hospital, Peking University, Beijing, China \\ Corresponding Author: Bo Li \\ Email address: li_bo@jlu.edu.cn
}

Background. Psychological disorders are common in diabetes mellitus (DM) patients, and the aim of this study was to estimate the prevalence of psychological distress and to determine the influence factors associated with psychological distress among DM patients in jilin province of China.

Methods and Materials. Multistage, stratified cluster sampling was used in this cross-sectional study. The 12-item General Health Questionnaire (GHQ-12) was used to assess psychological status with the total score of $\geq 4$ as the threshold for psychological distress.

Results. A total of 1,956 subjects with DM were included in the study. Out of this total diabetic participants, $524(26.8 \%)$ had psychological distress. Multiple logistic regression analysis showed that low educational level, divorce or separation from one's spouse, low family average monthly income, short sleep duration, being aware of DM status, and multiple co-morbidities are positively associated with psychological distress (all $P<0.05$ ).

Conclusions. This study revealed a high rate of psychological distress among DM population in Jilin province. Low educational level, divorce or separation from one's spouse, low family average monthly income, short sleep duration, awareness of DM status, and multiple co-morbidities are all associated with psychological distress among our study subjects. Interventions to control these factors are needed to address the psychological problems among diabetics in Jilin Province. 
1

4 Prevalence and correlates of psychological distress among diabetes mellitus adults in Jilin

5 province in China: a cross-sectional study

6
Title page

Shuang Qiu' ${ }^{1 \oplus}$, Hongxuan Sun ${ }^{14}$, Yawen $\mathrm{Liu}^{1}$, Joseph Sam Kanu${ }^{1}$, Ri Li ${ }^{1}$, Yaqin $\mathrm{Yu}^{1}$, Xufeng Huang $^{2}$, Bo Li ${ }^{1 *}$ and Xiangyang Zhang ${ }^{3 *}$

1 Department of Epidemiology and Biostatistics, School of Public Health, Jilin University, Changchun 130021, China;

2 Illawarra Health and Medical Research Institute, School of Medicine, University of Wollongong, 2522, Australia;

3 Psychiatry Research Center, Beijing Hui-Long-Guan hospital, Peking University, Beijing, 100096, China

I Shuang Qiu and Hongxuan Sun contributed equally to this article.

* Correspondence to:

Bo Li ${ }^{*}$ Email: li_bo@jlu.edu.cn

Xiangyang Zhang ${ }^{3 *}$ Email: zhangxy@gmail.com 
42

43

44

45

46

47

48

49

50

51

52

53

54

55

56

57

58

59

60

61

62

63

64

65

66

67

68

69

70

71

72

73

74

75

76

77

78

79

80

81

82

\section{Abstract:}

Background. Psychological disorders are common in diabetes mellitus (DM) patients, and the aim of this study was to estimate the prevalence of psychological distress and to determine the influence factors associated with psychological distress among DM patients in Jilin province of China.

Methods and Materials. Multistage, stratified cluster sampling was used in this cross-sectional study. The 12-item General Health Questionnaire (GHQ-12) was used to assess psychological status with the total score of $\geq 4$ as the threshold for psychological distress.

Results. A total of 1,956 subjects with DM were included in the study. Out of this total diabetic participants, 524 (26.8\%) had psychological distress. Multiple logistic regression analysis showed that low educational level, divorce or separation from one's spouse, low family average monthly income, short sleep duration, being aware of DM status, and multiple co-morbidities are positively associated with psychological distress (all $P<0.05$ ).

Conclusions. This study revealed a high rate of psychological distress among DM population in Jilin province. Low educational level, divorce or separation from one's spouse, low family average monthly income, short sleep duration, awareness of DM status, and multiple comorbidities are all associated with psychological distress among our study subjects. Interventions to control these factors are needed to address the psychological problems among diabetics in Jilin Province.

\section{Introduction}

Diabetes mellitus (DM) is one of the most common chronic metabolic diseases, and is a major health problem in many countries (Fisher et al. 2012; Whiting et al. 2011). In 2010, estimated 285 million people were affected by DM globally, and DM prevalence is expected to increase to 438 million people by 2030 (Raval et al. 2010). Rapid economic development and the subsequent changes in lifestyle have led to the widespread occurrence of DM (Guariguata et al. 2014). China has the largest diabetic population worldwide, and DM prevalence is estimated to be $11.6 \%$, representing nearly 113.9 million Chinese adults (Xu et al. 2013).

$\mathrm{DM}$ is not only associated with micro and macro vascular complications, such as increased risk of cardiovascular disease, diabetic nephropathy, retinopathy, neuropathy and lower extremity amputations, but may also influence physical functions, social interaction and mental well-being (Jhita et al. 2014; Shin et al. 2014).

Accumulating evidence suggests that psychological disorders are common in DM patients, and that DM patients are at substantial risk of heightened depression, anxiety, and stress (Anderson et al. 2001; Odusan et al. 2012; Raymond \& Lovell 2016; Roy \& Lloyd 2012; Yu et al. 2016).

Psychological disorders of DM patients are significantly associated with non-adherence to 
83 healthy lifestyle guidelines, thus increasing the risk for serious complications that may decrease patients' quality of life and result in premature death (Ducat et al. 2014; Gonzalez et al. 2008). Using the 12-item General Health Questionnaire (GHQ-12), Zubair et al. reported that 68.5\% of their study participants that scored more than 4 points had depressive symptoms, indicating that DM patients with psychological distress are more prone to depression (Zubair et al. 2014). Thus, GHQ-12 as a general measure of psychological distress is a simple and useful instrument for healthcare practitioners to evaluate the overall psychological status of DM patients.

Although many studies have focused on the link between psychological disorders and DM, epidemiological data on the prevalence and correlates of psychological distress among DM population in Jilin Province are limited. The aims of the study were: (1) to estimate the prevalence of psychological distress among DM patients in Jilin Province; (2) to determine the influence factors associated with psychological distress among DM patients in Jilin Province; and (3) to provide proper references for relevant departments.

\section{Materials and Methods}

\section{Study Population}

This study was conducted using a survey of chronic disease and risk factors among adults (aged 18-79 years) in Jilin province of China in 2012. The sample size was calculated considering the prevalence of chronic diseases investigated in this survey (varying from 0.02 to 0.99), two-tailed confidence level ( a ) of $95 \%$, and absolute error varying from 0.01 to 0.10 were used. The ultimate target sample size was estimated to be 25,240, which accounts for approximately $1 \%$ of the total adult population of Jilin province. We used multistage stratified cluster random sampling method to select a representative sample of permanent residents who had lived in Jilin province within 9 regions (Changchun, Jilin, Siping, Liaoyuan, Tonghua, Baishan, Songyuan, Baicheng and Yanbian) for at least six months. Then, we randomly selected clusters of four districts or counties from each of the nine regions using probability proportional to size (PPS) sampling. We selected 32 districts or counties, 95 towns or communities, and 45 units. Finally, we randomly selected one adult resident from each household in the selected units. The detailed sampling process has been described previously (Wang et al. 2014; Wang et al. 2015).

All participants gave informed consents before being recruited in the study. We adhered to the bioethics principles of the Declaration of Helsinki, and our study was authorized by the Ethics Committee of the School of Public Health of Jilin University (Reference Number: 2012-R-011) and the Bureau of Public Health of Jilin Province (Reference Number: 2012-10).

\section{Data Collection and Measurement}

Personal Health Questionnaire

We used an interviewer administered questionnaire to obtain information from our study 
subjects. The questionnaire was designed by our project team, and primarily included demographic factors (gender, age, race, community, educational level, marital status, occupation, and family average monthly income), as well as other information such as daily sleep duration and anthropometric measurements. The Mandarin Chinese language was used to design the questionnaire, and the questionnaire was administered in Chinese by investigators who could speak Mandarin Chinese and had received uniform training on the administration of the questionnaire.

\section{GHQ-12}

The GHQ-12, a shortened version of a 60-item screening tool developed by Goldberg in 1970, is a widely-used instrument for assessing psychiatric morbidity, especially to screen for depression and anxiety disorders (Goldberg et al. 1997). It has recently been adapted as a screening tool for psychological distress in various populations (Cuellar-Flores et al. 2014; Higuchi et al. 2016; Yi et al. 2016). It has been well-validated for general Chinese populations (Yang et al. 2003; Zhou et al. 2013). The GHQ-12 includes 12 questions, each with two response options (Yes or No). Each item is scored as either 0 (less or no more than usual) or 1 (more or much more than usual), for a maximum total score of 12. Higher scores indicate more psychological problems. According to the total score of the GHQ-12, participants scoring 4 or more are considered to be in psychological distress (Phillips et al. 2009).

\section{Baseline clinical data}

Fasting plasma glucose (FPG) was measured from participants who had fasted for 10 or more hours overnight. A small drop of blood was taken from one finger, placed onto a strip of paper and the glucose level measured using a Bayer Bai Ankang fingertip blood glucose monitoring machine.

$\mathrm{DM}$ was defined as either a fasting plasma glucose level $\geq 7.0 \mathrm{mmol} / \mathrm{L}$, according to the Chinese Guidelines on the prevention and treatment of Type 2 Diabetes (Society 2008), or selfreported diagnosed DM by a medical doctor in a hospital. Those self reported patients were considered to be aware of their DM status, and those who were only diagnosed during our investigation were considered to be unaware of their DM status.

Body mass index (BMI) was categorized into two groups: underweight or normal weight $\left(\mathrm{BMI}<24 \mathrm{~kg} / \mathrm{m}^{2}\right.$ ), and overweight or obesity (BMI $\left.\geq 24 \mathrm{~kg} / \mathrm{m}^{2}\right)($ Zhou 2002).

Number of co-morbid diseases was defined as a count of the following chronic diseases reported simultaneously with DM by patients, including hyperlipidemia, hypertension, cerebrovascular disease, coronary heart disease and myocardial infarction, cataract, gout, and hyperthyroidism. Chronic diseases were determined by participants who self-reported having previous diagnosis of the diseases from a health professional. DM patients were categorized into 4 groups: without any co-morbid disease, only one kind of co-morbid disease, two, three or more co-morbid diseases.

\section{Socio-demographics}


Community was divided into two groups: urban (including those who lived in cities or towns) and rural (including the rest of the entire population).

We divided education into three levels: primary school and below (including those who never attended school and those whose highest level of education was primary school), junior high school (including those whose highest level of education was junior high school), and senior high/technical secondary school and above (including those whose highest level of education was high school, technical secondary school or university degree).

Marital status was divided into four groups: married (including those who were married and those co-habiting), never married, divorced or separated, and widowed.

We divided occupation into three groups: manual workers (including farmers, service workers, and those who were engaged in production work), mental workers (including office and other technical staff), and others (including students, unemployed, and retirees) (Wang et al. 2014; Zhang et al. 2016).

Family average monthly income was calculated as the ratio of the total family income to the number of family members in the household, and was classified into five groups: low income group ( $<500$ yuan/month), lower-middle group (500-1000 yuan/month), middle group (1000-2000 yuan/month), higher-middle group (2000-3000 yuan/month), and high income group ( $\geqslant 3000$ yuan/month), in line with the classification of the Jilin Provincial Bureau of Statistics.

\section{Quality control}

We performed a pilot study to assimilate the main study using a total of 190 participants. Issues that aroused during the pilot study were addressed before the main study. All data were processed by parallel double entry using EpiData 3.1 database.

\section{Statistical Analysis}

Descriptive statistics were used to summarize the numbers and percentages for categorical variables, and mean (standard deviation - S.D) and median (IQR) for continuous variables. Univariate logistic regression analyses were used to compare the rates of psychological distress between different participants' characteristics (gender, age, race, community, educational level, marital status, occupation, family average monthly income, daily sleep duration, BMI, family history of DM, number of co-morbid diseases, and the awareness of DM). Variables that were significant in the univariate logistic analyses were included in the final multiple logistic regression analyses. Multiple logistic regression analyses were performed to explore the association between participants' characteristics and psychological distress. The statistical tests were 2-tailed, and significance was defined as $P<0.05$. All data were analyzed using SPSS (Version 21.0, IBM SPSS, IBM Corp, Armonk, NY, USA).

\section{Results}


204 A total of 1,956 DM participants were recruited in this study with a mean age of 55.68 years 205 (S.D.=10.26). We present participants demographic characteristics and other information in 206 Table 1. The proportions of males (49.7\%) and females (50.3\%) were almost the same, as well as 207 the residence location of the participants - urban $(50.8 \%)$ or rural $(49.2 \%)$. Nine hundred and 208 fifty-nine participants (49\%) were 45-59 years old, which was the largest age group. More than $20990 \%$ of participants were Han nationality. We also observed that $60.5 \%$ of participants attained a 210 junior high school or higher level of education; $89.4 \%$ of participants were married; $56.3 \%$ of 211 participants had sleep duration of $\geq 7$ hours per day; 30.7\% of participants had family average 212 monthly income of 1000-2000 Yuan; 71.5\% of participants had no history of DM; and $67.6 \%$ of 213 participants were overweight or obese. More participants were engaged in manual work (47.3\%) 214 than mental labor (14.0\%), with $68.9 \%$ of participants being aware of their DM status. Less than 215 half (47.0\%) of participants had no other diseases.

216

Table 1 Participants characteristics $(\mathrm{N}=1,956)$

\begin{tabular}{|c|c|c|}
\hline Characteristics & $\mathrm{n}$ & $\%$ \\
\hline \multicolumn{3}{|l|}{ Gender } \\
\hline Male & 972 & 49.7 \\
\hline Female & 984 & 50.3 \\
\hline \multicolumn{3}{|l|}{ Age group(years) } \\
\hline $18-44$ & 267 & 13.7 \\
\hline $45-59$ & 959 & 49.0 \\
\hline $60-79$ & 730 & 37.3 \\
\hline \multicolumn{3}{|l|}{ Race } \\
\hline Han nationality & 1795 & 91.8 \\
\hline Non Han minority & 161 & 8.2 \\
\hline \multicolumn{3}{|l|}{ Community } \\
\hline Urban & 994 & 50.8 \\
\hline Rural & 962 & 49.2 \\
\hline \multicolumn{3}{|l|}{ Educational level } \\
\hline Primary school and below & 773 & 39.5 \\
\hline Junior high school & 520 & 26.6 \\
\hline Senior high/technical secondary school and above & 663 & 33.9 \\
\hline \multicolumn{3}{|l|}{ Marital status } \\
\hline Married & 1748 & 89.4 \\
\hline Never married & 25 & 1.3 \\
\hline Divorce or separate & 41 & 2.1 \\
\hline Widowed & 142 & 7.3 \\
\hline \multicolumn{3}{|l|}{ Occupation } \\
\hline Manual worker & 925 & 47.3 \\
\hline Mental worker & 274 & 14.0 \\
\hline Others & 757 & 38.7 \\
\hline
\end{tabular}




\begin{tabular}{lrr} 
Family average monthly income & & \\
(yuan/month) & & \\
$<500$ & 487 & 24.9 \\
$500-1000$ & 397 & 20.3 \\
$1000-2000$ & 600 & 30.7 \\
$2000-3000$ & 320 & 16.4 \\
$\geq 3000$ & 152 & 7.8 \\
Daily sleep duration (hours) & & \\
$<7$ & 854 & 43.7 \\
$\geq 7$ & 1102 & 56.3 \\
BMI * (kg/m2) & & \\
$<24$ & 601 & 30.7 \\
$\geq 24$ & 1323 & 67.6 \\
Family history of DM & & \\
No & 1398 & 71.5 \\
Yes & 558 & 28.5 \\
Number of co-morbid disease & & \\
0 & 920 & 47.0 \\
1 & 601 & 30.7 \\
2 & 312 & 16.0 \\
$\geq 3$ & 123 & 6.3 \\
Awareness of DM & & \\
Yes & 1347 & 68.9 \\
No & 609 & 31.1 \\
\hline
\end{tabular}

* Total percentage did not equal to $100 \%$ because of missing data.

217

We further performed analysis to explore the factors associated with psychological distress of DM participants. Population characteristics according to psychological distress are shown in Table 2. Mean GHQ-12 score was 2 (IQR 0-4). Out of the 1,956 patients, 524 (26.8\%) participants had psychological distress. Univariate analysis revealed that the rate of psychological distress significantly differed by gender, community, educational level, marital status, occupation, family average monthly income, daily sleep duration, number of co-morbid diseases, and the awareness of DM (all $P<0.05)$, but not by age ( $P=0.056)$, race $(P=0.472)$, BMI ( $P=0.073)$, and family history of DM $(P=0.126)$. Compared with male, female were more likely to have psychological distress $(O R=2.046[1.666,2.513])$. Urban participants were less prone to psychological distress $(\mathrm{OR}=0.628[0.513,0.769])$, compared with rural participants. Participants whose highest level of education was primary school were associated with a higher prevalence of psychological distress than those whose highest level of education was senior high school/technical secondary school $(O R=2.472[1.938,3.154])$. The $O R s(95 \% C I)$ were 3.074 $[1.651,5.725]$ for divorce /separate DM participants, and 1.692 [1.183, 2.420] for widowed DM participants. Compared with manual workers, mental workers were less likely to be distressed 
$233(O R=0.533[0.380,0.747])$. The prevalence of psychological distress was higher among 234 participants whose family average monthly income was less than 500 Yuan $(O R=3.100$ [1.958, 235 4.910]), or 500-1000 Yuan $(O R=2.214[1.387,3.535])$ than those whose income was $\geq 3000$ 236 Yuan. Participants with sleep duration of $<7$ hours per day were associated with a higher 237 prevalence of psychological distress than participants with sleep duration of $\geq 7$ hours $238(O R=1.464[1.198,1.790])$. Participants whose co-morbid disease was 2 (OR=1.587 [1.194, $2392.110])$, and $\geq 3(O R=2.993[2.033,4.407])$ were more prone to have higher rate of 240 psychological distress than those without any other diseases. Participants who were aware of 241 their DM status were more likely to have psychological distress than those who were unaware $242(O R=1.523[1.214,1.911])$.

Table 2 Univariate analysis of factors associated with psychological distress $\quad(N=1,956)$

\begin{tabular}{|c|c|c|c|c|c|}
\hline Characteristics & Non-distressing & Distressing & $P$ & $O R$ & $95 \% C I$ \\
\hline Gender & & & $<0.001$ & & \\
\hline Male & $779(80.1)$ & 193(19.9) & & 1.000 & \\
\hline Female & $653(66.4)$ & $331(33.6)$ & & 2.046 & $1.666-2.513$ \\
\hline Age group(years) & & & 0.056 & & \\
\hline $18-44$ & $195(73.0)$ & $72(27.0)$ & & 1.000 & \\
\hline $45-59$ & $724(75.5)$ & $235(24.5)$ & & 0.879 & $0.646-1.196$ \\
\hline $60-79$ & $513(70.3)$ & $217(29.7)$ & & 1.146 & $0.837-1.567$ \\
\hline Race & & & 0.472 & & \\
\hline Han nationality & $1311(73.0)$ & $485(27.0)$ & & 1.000 & \\
\hline Non Han minority & $121(75.6)$ & $39(24.4)$ & & 0.871 & $0.598-1.268$ \\
\hline Community & & & $<0.001$ & & \\
\hline Rural & $660(68.6)$ & $302(31.4)$ & & 1.000 & \\
\hline Urban & $772(77.7)$ & $222(22.3)$ & & 0.628 & $0.513-0.769$ \\
\hline Educational level & & & $<0.001$ & & \\
\hline Senior school and above ${ }^{a}$ & $538(81.1)$ & $125(18.9)$ & & 1.000 & \\
\hline Junior high school & $403(77.5)$ & $117(22.5)$ & & 1.250 & $0.941-1.659$ \\
\hline Primary school and below & $491(63.5)$ & $282(36.5)$ & & 2.472 & $1.938-3.154$ \\
\hline Marital status & & & $<0.001$ & & \\
\hline Married & $1303(74.5)$ & $445(25.5)$ & & 1.000 & \\
\hline Never married & $19(76.0)$ & $6(24.0)$ & & 0.925 & $0.367-2.330$ \\
\hline Divorce or separate & $20(48.8)$ & $21(51.2)$ & & 3.074 & $1.651-5.725$ \\
\hline Widowed & $90(63.4)$ & $52(36.6)$ & & 1.692 & $1.183-2.420$ \\
\hline Occupation & & & 0.001 & & \\
\hline Manual worker & $652(70.5)$ & $273(29.5)$ & & 1.000 & \\
\hline Mental worker & $224(81.8)$ & $50(18.2)$ & & 0.533 & $0.380-0.747$ \\
\hline Others & $556(73.4)$ & $201(26.6)$ & & 0.863 & $0.697-1.070$ \\
\hline Monthly income $b$ & & & $<0001$ & & \\
\hline
\end{tabular}




\begin{tabular}{|c|c|c|c|c|c|}
\hline$\geq 3000$ & $126(82.9)$ & $26(17.1)$ & & 1.000 & \\
\hline $2000-3000$ & 213(83.9) & $41(16.1)$ & & 0.933 & $0.544-1.598$ \\
\hline $1000-2000$ & 494(79.3) & $129(20.7)$ & & 1.265 & $0.795-2.014$ \\
\hline $500-1000$ & $302(68.6)$ & $138(31.4)$ & & 2.214 & $1.387-3.535$ \\
\hline$<500$ & $297(61.0)$ & $190(39.0)$ & & 3.100 & $1.958-4.910$ \\
\hline Daily sleep duration (hours) & & & $<0.001$ & & \\
\hline$\geq 7$ & $843(76.5)$ & $259(23.5)$ & & 1.000 & \\
\hline$<7$ & $589(69.0)$ & $265(31.0)$ & & 1.464 & $1.198-1.790$ \\
\hline BMI * $(\mathrm{kg} / \mathrm{m} 2)$ & & & 0.073 & & \\
\hline$<24$ & $424(70.5)$ & $177(29.5)$ & & 1.000 & \\
\hline$\geq 24$ & $985(74.5)$ & $338(25.5)$ & & 0.822 & $0.663-1.019$ \\
\hline Family history of DM & & & 0.126 & & \\
\hline No & $1037(74.2)$ & $361(25.8)$ & & 1.000 & \\
\hline Yes & $395(70.8)$ & $163(29.2)$ & & 1.185 & $0, .953-1.475$ \\
\hline Number of co-morbid disease & & & $<0.001$ & & \\
\hline 0 & $714(77.6)$ & $206(22.4)$ & & 1.000 & \\
\hline 1 & $438(72.9)$ & $163(27.1)$ & & 1.290 & $1.017-1.636$ \\
\hline 2 & $214(68.6)$ & $98(31.4)$ & & 1.587 & $1.194-2.110$ \\
\hline$\geq 3$ & $66(53.7)$ & $57(46.3)$ & & 2.993 & $2.033-4.407$ \\
\hline Awareness of DM & & & $<0.001$ & & \\
\hline No & 479 (78.7) & $130(21.3)$ & & 1.000 & \\
\hline Yes & $953(70.7)$ & $394(29.3)$ & & 1.523 & $1.214-1.911$ \\
\hline
\end{tabular}

* Total percentage did not equal to $100 \%$ because of missing data. Data are presented as n(\%); OR Odds Ratio, CI confidence interval

a Senior high/technical secondary school and above

b Family average monthly income (yuan/month)

Table 3 shows the results of multivariate logistic regression analysis. This analysis revealed no significant difference in psychological distress by community and occupations $(P>0.05)$. However, we found significant differences in psychological distress by educational level, marital status, family average monthly income, daily sleep duration, the number of co-morbid diseases, and the awareness of DM after considering the effect of confounding factors $(P<0.05)$.

Participants who never attended school and those whose highest level of education was primary school were associated with a higher prevalence of psychological distress than those whose highest level of education was senior high school/technical secondary school $(O R=1.474$ [1.087, 1.999], $P=0.013)$. Divorced or separated participants were more likely to have psychological distress than married participants $(O R=3.434[1.772,6.653], P<0.001)$. Participants whose family average monthly income was less than 500 Yuan $(O R=2.282$ [1.377, 3.781], $P=0.001)$, or 500-1000 Yuan $(O R=1.728$ [1.045, 2.856], $P=0.033)$ were associated with a higher prevalence of psychological distress than those whose income was $\geq 3000$ Yuan. Participants who were aware of their DM status were more likely to develop psychological 
259 distress $(O R=1.305[1.022,1.667], P=0.033)$. Participants with sleep duration of $<7$ hours per 260 day were more likely to have psychological distress than participants with sleep duration of $\geq 7$ 261 hours $(O R=1.522$ [1.231, 1.883], $P<0.001)$. Participants who had 2 kinds of other diseases $262(O R=1.534[1.129,2.084], P=0.006)$, and three or more other diseases $(O R=2.473[1.635,3.739]$, $263 P<0.001)$ were associated with a lower prevalence of psychological distress than participants 264 without any other diseases.

Table 3 Multivariate analysis of factors associated with psychological distress

\begin{tabular}{|c|c|c|c|c|c|c|c|}
\hline \multirow{2}{*}{ Variables } & \multirow{2}{*}{$\beta$} & \multirow{2}{*}{ S.E. } & \multirow{2}{*}{ Wald } & \multirow{2}{*}{$P$} & \multirow{2}{*}{ OR } & \multicolumn{2}{|c|}{$95 \% C I$} \\
\hline & & & & & & Lower & Upper \\
\hline \multicolumn{8}{|l|}{ Educational level } \\
\hline Senior high school and above ${ }^{a}$ & & & & & 1.000 & & \\
\hline Junior high school & -0.008 & 0.156 & 0.003 & 0.958 & 0.992 & 0.731 & 1.346 \\
\hline Primary school and below & 0.388 & 0.156 & 6.217 & 0.013 & 1.474 & 1.087 & 1.999 \\
\hline \multicolumn{8}{|l|}{ Marital status } \\
\hline Married & & & & & 1.000 & & \\
\hline Never married & 0.178 & 0.496 & 0.129 & 0.720 & 1.194 & 0.452 & 3.155 \\
\hline Divorce or separate & 1.234 & 0.337 & 13.365 & $<0.001$ & 3.434 & 1.772 & 6.653 \\
\hline Widowed & 0.132 & 0.199 & 0.441 & 0.507 & 1.141 & 0.773 & 1.686 \\
\hline \multicolumn{8}{|l|}{ Monthly income b } \\
\hline$\geq 3000$ & & & & & 1.000 & & \\
\hline $2000-3000$ & -0.112 & 0.282 & 0.157 & 0.692 & 0.894 & 0.515 & 1.554 \\
\hline $1000-2000$ & 0.086 & 0.248 & 0.120 & 0.729 & 1.090 & 0.671 & 1.771 \\
\hline $500-1000$ & 0.547 & 0.256 & 4. 545 & 0.033 & 1.728 & 1.045 & 2.856 \\
\hline$<500$ & 0.825 & 0.258 & 10.259 & 0.001 & 2.282 & 1.377 & 3.781 \\
\hline \multicolumn{8}{|l|}{ Awareness of DM } \\
\hline No & & & & & 1.000 & & \\
\hline Yes & 0.266 & 0.125 & 4.540 & 0.033 & 1.305 & 1.022 & 1.667 \\
\hline \multicolumn{8}{|l|}{ Daily sleep duration (hours) } \\
\hline$\geq 7$ & & & & & 1.000 & & \\
\hline$<7$ & 0.420 & 0.108 & 15.030 & $<0.001$ & 1.522 & 1.231 & 1.883 \\
\hline \multicolumn{8}{|l|}{ Number of co-morbid disease } \\
\hline 0 & & & & & 1.000 & & \\
\hline 1 & 0.152 & 0.129 & 1.397 & 0.237 & 1.164 & 0.905 & 1.498 \\
\hline 2 & 0.428 & 0.156 & 7.488 & 0.006 & 1.534 & 1.129 & 2.084 \\
\hline$\geq 3$ & 0.905 & 0.211 & 18.416 & $<0.001$ & 2.473 & 1.635 & 3.739 \\
\hline
\end{tabular}




\section{Discussion}

This population-based study adds to the literature that the prevalence of psychological distress (GHQ-12 total score $\geq 4$ ) among DM patients in Jilin province of China is $26.8 \%$, higher than that the 18.9\% reported for England and Scottish DM population (Hamer et al. 2010), also higher than the Quebec and Canada DM population (22.1\%) (Smith et al. 2013). The inconsistency may be partly due to the disparities in assessment instruments, sampling methods, and the definition of psychological distress.

Similar to other studies (Tellez-Zenteno \& Cardiel 2002; Yang et al. 2009), we found that low educational levels were associated with increased risk of psychological distress. Patients with lower education levels were less knowledgeable about the association between DM and mental disorders, more difficult to understand how to moderate their mental stress, and consequently had a higher psychological well-being.

Many researchers concluded that marriage has a protective effect on mental health (Fu \& Noguchi 2016; Hughes \& Waite 2009). In our study, divorce or separation from one's spouse is the most significant factor associated with psychological distress. This is concordant with the findings of other researchers revealing that divorce or separation is associated with poor psychological well-being (Tellez-Zenteno \& Cardiel 2002). Divorced or separated participants may have issues of taking care of their parents, raising children alone, and trying to cope with the divorce and the burden of their disease. All these factors may have long-term negative effects on the mental health of these patients. Our results also showed no significant difference in psychological distress between widowed participants and married participants, which is inconsistent with the report by Akena and team (Akena et al. 2014). This may be related to the differences in widowhood duration and gender. Perkins and co-authors concluded that long-term (widowed 0 to 4 or $10+$ years) widowhood predicts worse health for women, but not for men (Perkins et al. 2016). In our study, we adjusted the confounding influence of gender using multiple logistic regression, but we did not obtained information about widowhood duration which need further research.

Our study demonstrated that participants with low family average monthly income were more prone to psychological distress. This accords with a study in central China by Yang and team (Yang et al. 2009). Management of DM is associated with long term financial burden (Arnold et al. 2016). Failure to cope with this heavy financial burden might be associated with psychological disturbances. It is not surprising in our study that participants with low family average monthly income had a great likelihood of developing psychological distress. In a study among low and middle income countries, Leone et al. noted that the occurrence of depression among diabetic patients seems to be associated with lower socioeconomic status (Leone et al. 2012).

Participants who were aware of their DM status were more likely to have psychological distress. A meta-analysis of 13 studies by Nouwen and colleagues concluded that patients who were aware of DM had increased risk of depression relative to patients that were unaware 
308 (Nouwen et al. 2011). Our finding is consistent with the findings of other studies (Domingo et al. 2015; Knol et al. 2007; Olvera et al. 2016). These psychological problems in people with DM might be related to the consequences of the burden of DM. Participants who were aware of their DM status have to change their poor health behaviors (e.g., smoking, high fat diet, and low physical activity), or take their anti-diabetic medications. The need for monitoring their blood glucose and medical complications or related diseases may induce psychological problems.

Poor sleep is an important etiology of depression (Chang et al. 2012; Paunio et al. 2014). This observation is in agreement with our finding that participants with short sleep durations had higher likelihood of developing psychological distress. Yu and team investigated the prevalence of depression among rural residents with DM patients in China, and reported that shorter sleep duration increases the risk of depressive symptoms ( $\mathrm{Yu}$ et al. 2016). In addition, frequent urination that is a major symptom of DM may cause discomfort to diabetic patients and reduce their quality of sleep. Sleep quality can be a potential mediator between psychological distress and diabetes quality of life. In a study on veterans, Seligowski and co-authors found that sleep quality has a partial indirect effect on the relationships between the symptoms of depression and the quality of life of diabetic patients, and between the symptoms of anxiety and diabetes quality of life (Seligowski et al. 2013).

Participants who co-morbid more than or equal to 2 kinds of other diseases were associated with a higher prevalence of psychological distress. Similarly, a study from Palestine by Sweileh et al showed that DM participants with combined multiple additional illnesses were more prone to develop depressive symptoms (Sweileh et al. 2014). Chronic pain, somatic discomfort, and restrictions on one's social life are common consequences of chronic medical illnesses which lower quality of life and increase the risk for psychological disorders (Agborsangaya et al. 2013).

Our study involved a large and representative sample of DM participants and a good response rate from these participants in Jilin province. We considered not only demographic factors but also baseline clinical factors possibly associated with psychological distress. Our study revealed a high rate of psychological distress among DM population in Jilin province in China and some correlates of psychological distress. Prevention and treatment are urgently needed to address the public health problem of psychological distress among DM population and to prevent them from developing more serious psychological disorders. Chinese government should pay attention to DM-related mental diseases, increase investment for health education and promotion, inform patients about the harm of DM-related mental diseases and formulate methods to reduce psychological distress, strengthen the primary mental health care system, increase financial subsidies for low income families, and put in place DM and other chronic diseases prevention and treatment measures.

However, our results may be biased by the method used to confirm DM. We only used FPG levels to confirm DM, as we did not perform postprandial glucose tolerance test or measure glycosylated hemoglobin levels. In addition, other unmeasured variables such as time since diagnosis, social support, and diabetes self-efficacy, might have been important to adjust for in our study. Third, because of the cross-sectional design, the interpretation of causal relationships between risk factors and the development of psychological distress is limited. Longitudinal 
349

350

351

352

353

354

355

356

357

358

359

360

361

362

363

364

365

366

367

368

369

370

371

372

373

374

375

376

377

378

379

380

381

382

383

384

385

386

387

388

389

studies are also needed to investigate the predictors of psychological distress in Chinese DM population in the future.

\section{Conclusions}

Psychological distress is highly prevalent among DM population in Jilin province, China. Several factors are associated with psychological distress among diabetic patients in Jilin Province (low educational level, divorce or separation from one's spouse, low family average monthly income, short sleep duration, being aware of DM status, and multiple co-morbidities). To effectively improve the quality of life of diabetics in this part of China, relevant health authorities should adequately address these factors.

Acknowledgements: The authors would like to thank our survey team members (Changgui Kou, Yong Li, Qing Zhen, Yuchun Tao, Huan He, Yulu Gu and Chang Wang et al), participants and volunteers for their effort in this study.

\section{References}

Agborsangaya CB, Lau D, Lahtinen M, Cooke T, and Johnson JA. 2013. Health-related quality of life and healthcare utilization in multimorbidity: results of a cross-sectional survey. Qual Life Res 22:791-799. $10.1007 / \mathrm{s} 11136-012-0214-7$

Akena D, Kadama P, Ashaba S, Akello C, Kwesiga B, Rejani L, Okello J, Mwesiga EK, and Obuku EA. 2014. The association between depression, quality of life, and the health care expenditure of patients with diabetes mellitus in Uganda. J Affect Disord 174c:7-12. 10.1016/j.jad.2014.11.019

Anderson RJ, Freedland KE, Clouse RE, and Lustman PJ. 2001. The prevalence of comorbid depression in adults with diabetes: a meta-analysis. Diabetes Care 24:1069-1078.

Arnold M, Beran D, Haghparast-Bidgoli H, Batura N, Akkazieva B, Abdraimova A, and Skordis-Worrall J. 2016. Coping with the economic burden of Diabetes, TB and co-prevalence: evidence from Bishkek, Kyrgyzstan. BMC Health Serv Res 16:118. 10.1186/s12913-016-1369-7

Chang JJ, Salas J, Habicht K, Pien GW, Stamatakis KA, and Brownson RC. 2012. The association of sleep duration and depressive symptoms in rural communities of Missouri, Tennessee, and Arkansas. J Rural Health 28:268-276. 10.1111/j.1748-0361.2011.00398.x

Cuellar-Flores I, Sanchez-Lopez MP, Liminana-Gras RM, and Colodro-Conde L. 2014. The GHQ-12 for the assessment of psychological distress of family caregivers. Behav Med 40:65-70. 10.1080/08964289.2013.847815

Domingo AK, Asmal L, Seedat S, Esterhuizen TM, Laurence C, and Volmink J. 2015. Investigating the association between diabetes mellitus, depression and psychological distress in a cohort of South African teachers. $S$ Afr Med J 105:1057-1060. 10.7196/SAMJ.2015.v105i12.9843

Ducat L, Philipson LH, and Anderson BJ. 2014. The mental health comorbidities of diabetes. Jama 312:691-692. 10.1001/jama.2014.8040

Fisher EB, Chan JC, Nan H, Sartorius N, and Oldenburg B. 2012. Co-occurrence of diabetes and depression: 
390

391

392

393

394

395

396

397

398

399

400

401

402

403

404

405

406

407

408

409

410

411

412

413

414

415

416

417

418

419

420

421

422

423

424

425

426

427

428

429

430

conceptual considerations for an emerging global health challenge. J Affect Disord 142 Suppl:S56-66. 10.1016/s0165-0327(12)70009-5

$\mathrm{Fu}$ R, and Noguchi H. 2016. Does Marriage Make Us Healthier? Inter-Country Comparative Evidence from China, Japan, and Korea. PLoS One 11:e0148990. 10.1371/journal.pone.0148990

Goldberg DP, Gater R, Sartorius N, Ustun TB, Piccinelli M, Gureje O, and Rutter C. 1997. The validity of two versions of the GHQ in the WHO study of mental illness in general health care. Psychol Med 27:191-197.

Gonzalez JS, Peyrot M, McCarl LA, Collins EM, Serpa L, Mimiaga MJ, and Safren SA. 2008. Depression and diabetes treatment nonadherence: a meta-analysis. Diabetes Care 31:2398-2403. 10.2337/dc08-1341

Guariguata L, Whiting DR, Hambleton I, Beagley J, Linnenkamp U, and Shaw JE. 2014. Global estimates of diabetes prevalence for 2013 and projections for 2035. Diabetes Res Clin Pract 103:137-149. 10.1016/j.diabres.2013.11.002

Hamer M, Stamatakis E, Kivimaki M, Pascal Kengne A, and Batty GD. 2010. Psychological distress, glycated hemoglobin, and mortality in adults with and without diabetes. Psychosom Med 72:882-886. 10.1097/PSY.0b013e3181f6696e

Higuchi Y, Inagaki M, Koyama T, Kitamura Y, Sendo T, Fujimori M, Uchitomi Y, and Yamada N. 2016. A crosssectional study of psychological distress, burnout, and the associated risk factors in hospital pharmacists in Japan. BMC Public Health 16:534. 10.1186/s12889-016-3208-5

Hughes ME, and Waite LJ. 2009. Marital biography and health at mid-life. J Health Soc Behav 50:344-358.

Jhita T, Petrou S, Gumber A, Szczepura A, Raymond NT, and Bellary S. 2014. Ethnic differences in health related quality of life for patients with type 2 diabetes. Health Qual Life Outcomes 12:83. 10.1186/1477-7525-1283

Knol MJ, Heerdink ER, Egberts AC, Geerlings MI, Gorter KJ, Numans ME, Grobbee DE, Klungel OH, and Burger H. 2007. Depressive symptoms in subjects with diagnosed and undiagnosed type 2 diabetes. Psychosom Med 69:300-305. 10.1097/PSY.0b013e31805f48b9

Leone T, Coast E, Narayanan S, and de Graft Aikins A. 2012. Diabetes and depression comorbidity and socioeconomic status in low and middle income countries (LMICs): a mapping of the evidence. Global Health 8:39. 10.1186/1744-8603-8-39

Nouwen A, Nefs G, Caramlau I, Connock M, Winkley K, Lloyd CE, Peyrot M, and Pouwer F. 2011. Prevalence of depression in individuals with impaired glucose metabolism or undiagnosed diabetes: a systematic review and meta-analysis of the European Depression in Diabetes (EDID) Research Consortium. Diabetes Care 34:752-762. 10.2337/dc10-1414

Odusan O, Ogunsemi O, and Olatawura M. 2012. Common mental disorders associated with 2-year diabetes incidence The Netherlands Study of Depression and Anxiety (NESDA). J Affect Disord 41:141-145. 10.1016/S0165-0327(12)70006-X

Olvera RL, Fisher-Hoch SP, Williamson DE, Vatcheva KP, and McCormick JB. 2016. Depression in Mexican Americans with diagnosed and undiagnosed diabetes. Psychol Med 46:637-646. $10.1017 / \mathrm{s} 0033291715002160$

Paunio T, Korhonen T, Hublin C, Partinen M, Koskenvuo K, Koskenvuo M, and Kaprio J. 2014. Poor sleep predicts symptoms of depression and disability retirement due to depression. J Affect Disord 172c:381-389. 10.1016/j.jad.2014.10.002

Perkins JM, Lee HY, James KS, Oh J, Krishna A, Heo J, Lee JK, and Subramanian SV. 2016. Marital status, 
431

432

433

434

435

436

437

438

439

440

441

442

443

444

445

446

447

448

449

450

451

452

453

454

455

456

457

458

459

460

461

462

463

464

465

466

467

468

469

470

471

widowhood duration, gender and health outcomes: a cross-sectional study among older adults in India. BMC Public Health 16:1032. 10.1186/s12889-016-3682-9

Phillips MR, Zhang J, Shi Q, Song Z, Ding Z, Pang S, Li X, Zhang Y, and Wang Z. 2009. Prevalence, treatment, and associated disability of mental disorders in four provinces in China during 2001-05: an epidemiological survey. Lancet 373:2041-2053. 10.1016/s0140-6736(09)60660-7

Raval A, Dhanaraj E, Bhansali A, Grover S, and Tiwari P. 2010. Prevalence \& determinants of depression in type 2 diabetes patients in a tertiary care centre. Indian J Med Res 132:195-200.

Raymond KL, and Lovell GP. 2016. Food addiction associations with psychological distress among people with type 2 diabetes. J Diabetes Complications 30:651-656. 10.1016/j.jdiacomp.2016.01.020

Roy T, and Lloyd CE. 2012. Epidemiology of depression and diabetes: a systematic review. J Affect Disord 142 Suppl:S8-21. 10.1016/s0165-0327(12)70004-6

Seligowski AV, Pless Kaiser AP, Niles BL, Mori DL, King LA, and King DW. 2013. Sleep quality as a potential mediator between psychological distress and diabetes quality of life in veterans with type 2 diabetes. $J$ Clin Psychol 69:1121-1131. 10.1002/jclp.21866

Shin JK, Shortridge-Baggett LM, Sachmechi I, Barron C, Chiu YL, Bajracharya B, and Bang H. 2014. Screening for type 2 diabetes mellitus in patients with mental illness: Application of a self-assessment score for diabetes mellitus risk. Psychiatry Res 220:1037-1042. 10.1016/j.psychres.2014.08.047

Smith KJ, Gariepy G, Pedneault M, Beland M, Clyde M, and Schmitz N. 2013. Exploring the association of psychological status with self-rated diabetes control: results from the Montreal evaluation of diabetes treatment study. Psychosomatics 54:35-43. 10.1016/j.psym.2012.08.002

Society CD. 2008. China Guideline for Type 2 Diabetes (2007 edition). National Medical Journal of China $88: 1227-1245$.

Sweileh WM, Abu-Hadeed HM, Al-Jabi SW, and Zyoud SH. 2014. Prevalence of depression among people with type 2 diabetes mellitus: a cross sectional study in Palestine. BMC Public Health 14:163. 10.1186/14712458-14-163

Tellez-Zenteno JF, and Cardiel MH. 2002. Risk factors associated with depression in patients with type 2 diabetes mellitus. Arch Med Res 33:53-60.

Wang C, Yu Y, Zhang X, Li Y, Kou C, Li B, Tao Y, Zhen Q, He H, Kanu JS, Huang X, Han M, and Liu Y. 2014. Awareness, treatment, control of diabetes mellitus and the risk factors: survey results from northeast China. PLoS One 9:e103594. 10.1371/journal.pone.0103594

Wang SB, D'Arcy C, Yu YQ, Li B, Liu YW, Tao YC, Wu YH, Zhang QQ, Xu ZQ, Fu YL, and Kou CG. 2015. Prevalence and patterns of multimorbidity in northeastern China: a cross-sectional study. Public Health 129:1539-1546. 10.1016/j.puhe.2015.06.013

Whiting DR, Guariguata L, Weil C, and Shaw J. 2011. IDF diabetes atlas: global estimates of the prevalence of diabetes for 2011 and 2030. Diabetes Res Clin Pract 94:311-321. 10.1016/j.diabres.2011.10.029

Xu Y, Wang L, He J, Bi Y, Li M, Wang T, Wang L, Jiang Y, Dai M, Lu J, Xu M, Li Y, Hu N, Li J, Mi S, Chen CS, Li G, Mu Y, Zhao J, Kong L, Chen J, Lai S, Wang W, Zhao W, and Ning G. 2013. Prevalence and control of diabetes in Chinese adults. Jama 310:948-959. 10.1001/jama.2013.168118

Yang J, Li S, and Zheng Y. 2009. Predictors of depression in Chinese community-dwelling people with type 2 diabetes. J Clin Nurs 18:1295-1304. 10.1111/j.1365-2702.2008.02703.x

Yang Y, Huang L, and Wu Z. 2003. Study on the appropriateness of the Chinese version of the General Health 
472

473

474

475

476

477

478

479

480

481

482

483

484

485

486

487

488

489
Questionnaire as a screening instrument for psychological disorders in mainland China. Chin $J$ Epid 24:769-773.

Yi S, Tuot S, Chhoun P, Pal K, Choub SC, and Mburu G. 2016. Prevalence and correlates of psychological distress among drug users in Phnom Penh, Cambodia. Int J Drug Policy 36:25-32. 10.1016/j.drugpo.2016.06.002

Yu S, Yang H, Guo X, Zheng L, and Sun Y. 2016. Prevalence of Depression among Rural Residents with Diabetes Mellitus: A Cross-Sectional Study from Northeast China. Int J Environ Res Public Health 13. 10.3390/ijerph13060542

Zhang P, Wang R, Gao C, Song Y, Lv X, Jiang L, Yu Y, Wang Y, and Li B. 2016. Types of Obesity and Its Association with the Clustering of Cardiovascular Disease Risk Factors in Jilin Province of China. Int $J$ Environ Res Public Health 13. 10.3390/ijerph13070685

Zhou BF. 2002. Predictive values of body mass index and waist circumference for risk factors of certain related diseases in Chinese adults--study on optimal cut-off points of body mass index and waist circumference in Chinese adults. Biomed Environ Sci 15:83-96.

Zhou X, Kang L, Sun X, Song H, Mao W, Huang X, Zhang Y, and Li J. 2013. Prevalence and risk factors of posttraumatic stress disorder among adult survivors six months after the Wenchuan earthquake. Compr Psychiatry 54:493-499. 10.1016/j.comppsych.2012.12.010

Zubair UB, Mansoor S, and Rana MH. 2014. Prevalence of depressive symptoms and associated socio-demographic factors among recruits during military training. J R Army Med Corps. 10.1136/jramc-2014-000253 